\section{LECTIO \\ Investidura del \\ Grado de Doctor Honoris \\ Causa del Doctor Romà de la Calle por la UJI-Martes 21 de noviembre de 2017, a las 18 horas, el Paranimf de la Universitat Jaume I \\ L'estètica com a filosofia pràctica en el context històric de la transició valenciana i fins a l'actualitat}

PROFESSOR ROMÀ DE LA CALLE

Catedrático de Estética y Teoría del Arte de la Universitat de València-Estudi General, ensayista y críico de arte. Ha sido Director del Instituto Universitario de Creatividad e Innovaciones Educativas de la Universitat de València y Presidente de la Real Academia de Bellas Artes de San Carlos (Valencia). Tras su jubilación, fue nombrado Profesor Honorario de la Universidad de Valencia.
$\Rightarrow$ Recibido 30/10/2017

$\checkmark$ Aceptado 02/12/2017

Excel-lentíssim senyor rector magnífic. Excel-lentíssimes autoritats, professors, col-legues, familiars i amics. Senyores i senyors.

Poques vegades, com en aquests moments, he estat tan plenament conscient de com la meua estreta i llarga vinculació amb la institució universitària ha condicionat, a fons, la meua vida i els meus objectius professionals i personals. Necessàriament doncs - tot seguint el fil d'aquestes reflexions, entrellaçades de sentiments- aquestes sentides paraules inicials han de ser de clar agraïment envers aquells amics i/o antics alumnes que van iniciar les gestions per a la proposta i concessió, en la meua persona, del grau del doctorat honoris causa, per part d'aquesta estimada Universitat Jaume I i també a tots els qui, en el seu moment, es van sumar al projecte que, en aquest solemne acte, culmina i es materialitza.

Es tracta, a més, d'agrair, recordar i compartir aquest esperit de satisfacció acadèmica — precisament en una conjuntura, tan especial — amb les persones i col-lectius que han treballat al meu costat - $\mathrm{i}$ jo al seu - en totes aquestes dècades — mig segled'especial dedicació a la docència, la recerca i la gestió cultural, en diverses universitats, tot pensant sempre, també, en l'obligada incidència, paral.lela i/o externa, sobre els respectius contextos socials. Nulla paedagogia sine ethica. 
Justament en aquest acte solemne, carregat d'emotivitat, amb l'atorgament públic i oficial, a tants nous doctors, del seu grau acadèmic, no puc estalviar-me de recordar, amerat de plurals i enfrontats sentiments que, fa exactament 47 anys, ja com a jove professor d'estètica, vaig viure també aquesta mateixa litúrgia iniciàtica col-lectiva. Malgrat tot, en aquell any de 1970, les universitats espanyoles vivíem, és clar, una conjuntura sociopolítica força diferent, difícil, resistent i compromesa. En realitat, m'arriscaria a dir, en aquest moment, gairebé mig segle després, que el compromís i la responsabilitat personals segueixen sent igual de ferms i convincents, tant en el vostre cas, com en el meu, envers la Universitat i la societat, ara i segur que també en el futur. Aquestes paraules meues arrepleguen un desig sincer i formulen una aposta explícita, destinada, de manera espontània, a tots els nous doctors. Enhorabona, doncs, a uns $i$ altres. Aquest acte, sens dubte, el recordareu, el recordarem, sempre.

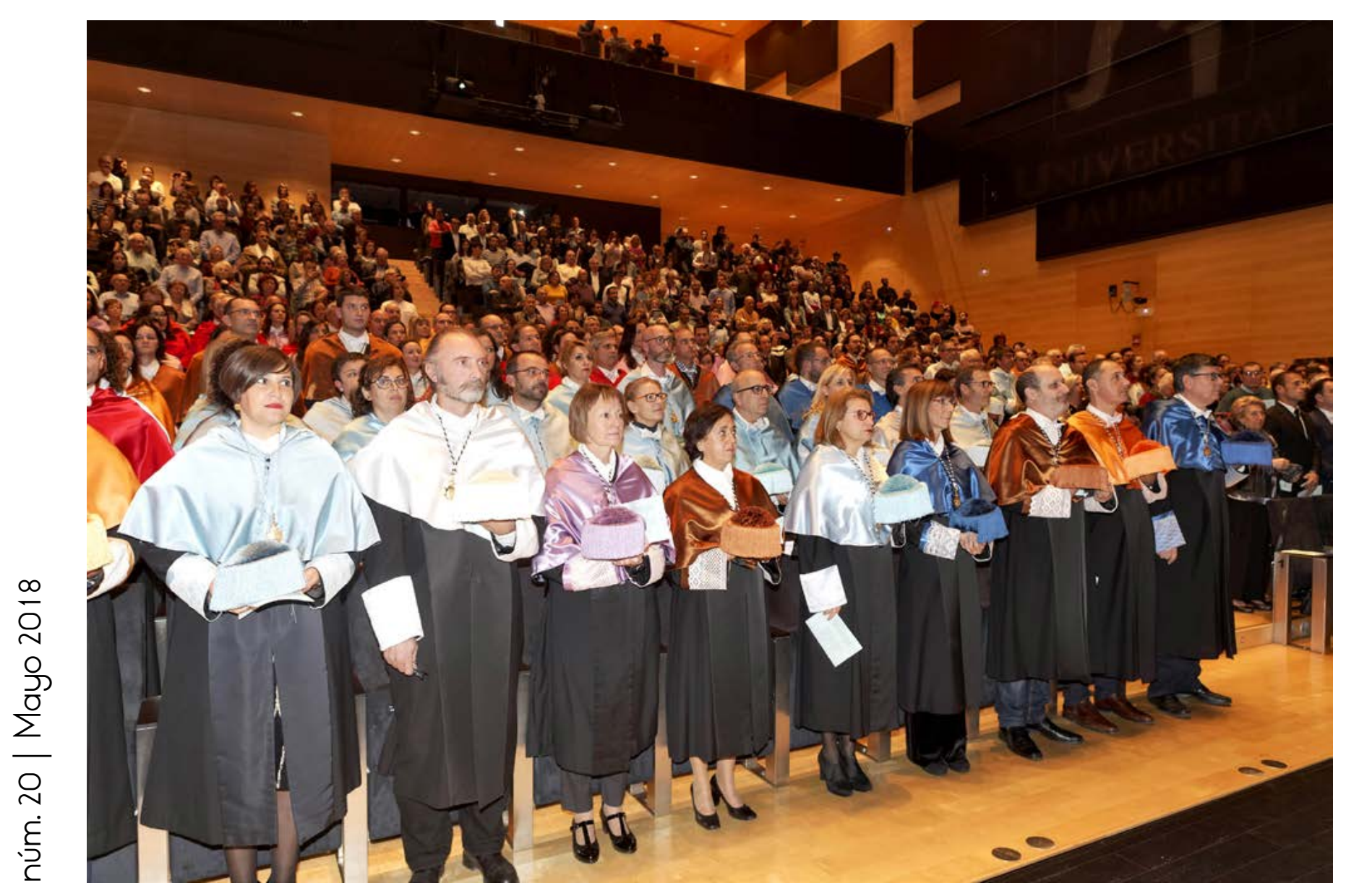

Així mateix, de manera molt especial després d'escoltar la seua expressiva Laudatio, desitge reconèixer, al professor - $\mathrm{i}$ sobretot amic - doctor Wenceslao Rambla, el grau de generositat mostrat envers la meua persona, a través de les seues ben articulades i emotives paraules. Moltes gràcies.

La veritat és que - a més de sentir-me commogut pel reconeixement i per l'es tima dels qui heu volgut i pogut acompanyar-me aquest dia- he de confessar que m'envaeix la puntual nostàlgia d'haver coronat un complex viatge d'activi tats $\mathrm{i}$ experiències, dedicat bàsicament al conreu intensiu de la filosofia pràctica que ara, generosament, es recorda i reconeix, en aquest acte acadèmic. És a dir en concret, al cultiu, la recerca, la pràctica i la difusió en els àmbits de l'estètica, la teoria de l'art i la crítica, concentrades, d'una manera força especial, al voltant de les arts visuals i les arts plàstiques contemporànies; també entorn dels imperatius inherents de l'educació artística, de l'estudi del nostre patrimoni cultural i de la nova museologia. Aquest seria, de fet, el mapa cartogràfic i el ventall vital d'una existència, per sort, atapeïda de somnis projectes, d'esforços, fites, tasques i col.laboracions compartides.
Reconec que sempre em vaig plantejar la filosofia com a eina útil i estratègic camí de reflexió aplicada, tot mirant directament cap a la vida i entrant a sac, en ella, sovint, quan calia, per les exigències de l'entorn. Mai la vaig entendre, certament - la filosofia - com a estricte reducte especulatiu, autònom i aillat. I si tot conreu de la filosofia — vaig pensar i encara ho pense - travessa i s'atura, necessàriament i dialècticament, d'una banda, en els meandres de la seua mateixa història, tampoc deixa d'exigir, per l'altra - a més - tota una operativa tensió interdisciplinària i expansiva al seu voltant.

He de fer palès que, des del principi, una de les meues explícites preocupacions disciplinàries sempre va ser el caràcter de no man's land que l'estètica, en general, havia conjuminat al llarg de la seua històrica diacronia, i que, operativament, encara propiciava, també, enmig de la seua realitat contemporània. El risc es presentava, per tant, enfront d'aquesta dilatada, incògnita i revulsiva terra de ningú, que volíem explorar, amb passió professional, però que creixia i mutava inexhaurible, entre les metamorfosis expandides de l'actual fet artístic i les possibilitats i transformacions imparables de la cultura contemporània, amb l'evident 
perill acadèmic «d'acabar sent més un diletant - extensiu - de moltes coses, que un veritable especialista». D'ací - senyores i senyors- la necessitat peremptòria que vàrem experimentar de definir territoris d'estudi apropiats, en cada cas, i de bastir ponts de relació entre tots ells.

Una vegada més -insistesc - estètica i història de l'estètica havien d'anar de la mà, igual que la filosofia mai deixarà de ser, tampoc, en part, la rememoració efectiva del seu passat, de la seua història Però - a més - seguia, per la meua ban$\mathrm{da}$, obsessionat per a aplicar la filosofia a la realitat circumdant. És a dir, en aquest cas, al plural domini de les arts, en el seu context sociocultural i, especialment, com he dit, al dilatat àmbit de les arts plàstiques i visuals, així com a la creixent dimensió aplicada als dominis de la il.lustració i del disseny, en la seua contemporaneïtat més immediata. Tot ens pareixia poc a aquell grup de joves professors que conformarem l'interdisciplinari «Col.lectiu d'Estudis de Comunicació Artística», $\propto$ en les darreries dels anys setanta, a la Uniㄱ versitat de València i que seria, després, 고 punt clau de la fèrtil diàspora acadèmica $\sum$ cap a altres universitats, entre elles, cla ㄱ està, també l'UJ.
Fins i tot, en el desenvolupament històric contemporani del marc de l'àrea d'estètica, a la Universitat espanyola, sempre vaig proposar i vaig donar suport, personalment — davant els col-legues de diferents universitats - a la urgent exigència, insistesc, de bastir sòlids ponts d'especialització i diversificació relacional entre l'estètica, com a filosofia aplicada, i les diferents àrees concretes artístiques existents. Es tractava d'entrellaçar plenament, d'aquesta manera, les arrels filosòfiques amb les plurals disciplines artístiques dels respectius camps d'intervenció i acollida.

Altrament -enfront de certes postures que propiciaven, a ultrança, una mena de restricció per a l'estètica, tancada en el seu particular reducte filosòfic - tenia clar que la presència de la nostra disciplina corria el risc de desaparèixer acadèmicament, de manera gradual, en certs àmbits d'aplicació a les arts, sense el desplegament d'un urgent diàleg interdisciplinari obert, franc, ambiciós i permanent. I així ha succeït, malauradament, en els darrers lustres, en determinats dominis puntuals, com poden ser, per exemple, els de l'arquitectura i l'enginyeria, entre d'altres.
Per la meua banda — com ja he ditla necessitat operativa i equilibrant de mantenir i alhora supervisar, d'una part la forta temptació especulativa, que tot filòsof, d'alguna manera, exercita i, per altra, de fomentar creixentment, així mateix, la directa aplicabilitat de la filosofia al camp de la praxi i de l'experiència de les arts es va convertir en l'estratègia fonamental per a apropar la tasca docent $\mathrm{i}$ investigadora a l'immediat camp aplicat de la crítica d'art, com a efectiva, eficient i determinant pedra de contrastació.

Aquest va ser aviat un dels nostres objectius-pont propiciats entre la Universitat i la societat: la creació compromesa de l'Associació Valenciana de Crítics d'Art (AVCA), la data fou l'any 1980, amb l'imprescindible suport del recordat Vicent Aguilera Cerni —que ja havia materialitzat aleshores el seu somni d'enllestir e Museu de Vilafamés, inaugurat el 1972i el suport convençut d'altres col.legues d'Estètica, d'Història de l'Art, de Belles Arts i també de l'àmbit del periodisme. Alguns d'aquells col-legues i amics, de l'Associació de Crítics --la qual encara gaudeix d'una bona salut social, operativa i compromesa-- ens acompanyen hui.
L'exercici de la crítica d'art es va transformar, llavors, entre nosaltres - ho saben bé els colllegues de l'àrea d'aquesta Universitat, que de prop ho visqueren i practicaren - en experimental camp d'actuació i en obligat camí de trànsit cap a l'eficaç acostament de la reflexió estètica i les seues diverses aplicacions al panorama actual de les arts plàstiques valencianes. Però també com a part fonamental de la docència, en les disciplines de la secció d'Història de l'Art. Tota una novetat, inusual abans, en aquella conjuntura dels inicis de la transició valenciana.

Operativament, es van entendre aquestes experiències com a oportuns i necessaris reajustaments interdisciplinaris, i van fer seua, des de l'àrea d'Estètica, no sense problemes, aquesta visió aplicada, oberta i dialogant de la nova orientació, projectada en l'art contemporani, a la seua fonamentació, al seu seguiment crític, a la seua potencialitat museològica i a la seua projecció social, des de les aules de la Universitat. Ens esforçàvem, de manera es pecial, per a prestar la màxima atenció al seguiment històric i a l'estudi gradual del context artístic contemporani del nostre país, força desatès acadèmicament llavors i, de fet, molt poc estudiat, oblidat en els darrers trams del franquisme. 
Allò sí que fou històricament una assignatura pendent, en aquelles dècades, entre els setanta i els noranta $i$, en realitat, el Departament d'Estètica i Teoria de les Arts va assumir efectivament —en aquell marc sociopolític de la dilatada transició- la tasca de normalitzar, tant com fóra possible, les relacions entre el fet artístic valencià i el seu abordatge i contextualització acadèmics, sempre des de la Universitat. Un fet que mai s'havia previst, com a calculada estratègia docent, ni produït, com a explícit objectiu pedagògic.

Aquest va ser el camí, operativament traçat, per a donar, entre nosaltres, efectivitat a l'estètica com a filosofia pràctica. Però, hi ha una reflexió personal, no menys destacada, que no voldria passar, tampoc, ara per alt. En comptes d'esqueixar aquell corpus filosòfic aplicat, i dividir-lo de manera immediata, en les seues diferents disciplines acadèmiques, sempre em va semblar, almenys des de l'àmbit de l'estètica — primer com a estudiant i després com a docent- que la categoria de rela$\infty \quad$ ció interdisciplinària era fonamental per a ㄱ assegurar el sosteniment metodològic i

금 la fluïdesa del marc mateix de la filosofia $\sum$ pràctica.
Des de l'afany de cercar una nova estètica era impossible, en efecte, no dialogar — a més de amb la història de l'art- per exemple, també amb l'antropologia, la sociologia, la psicologia, la teoria de la comunicació, la semiòtica o la cibernèti$\mathrm{ca}$, ateses les profundes arrels humanístiques existents en tota activitat poiètica, creativa, artística i transformadora. Diàlegs sempre, per cert, de doble direcció transdisciplinària.

El mateix caldria apuntar — senyores $\mathrm{i}$ senyors - respecte a l'estètica i els seus profunds i diversos enllaços i interseccions amb els dominis de l'ètica. l, a més a més, de l'estètica amb les seues compromeses aplicacions en l'àmbit de la cultura artística, en concret, de cara a la política, en la seua implantació social, ciutadana, educativa, tant individualment com collectivament enfocades. ¿Com no parlar, amb màxim compromís i responsabilitat, de polítiques i serveis culturals — des de la reflexió estètica - fins i tot, en els moments més aspres i preocupants de certs controls i censures culturals, efectivament viscuts, patits i recordats?

Nulla aesthetica sine ethica. És cert, aquest principi preceptiu estava clar, com a herència filosòfica compartida, des de la formulació històrica, per part de l'es- timat professor i amic José María Valverde, aquell crucial 1965, en dimitir de la seua càtedra d'Estètica en la Universitat Central de Barcelona, igual que féu aix mateix Antonio Tovar, en solidaritat amb els expulsats pel franquisme, professors Tierno Galván, López Aranguren i García Calvo; però també els catedràtics Montero Díaz i Aguilar Navarro. Fou tot un càstig i una neteja ideològica, que volia ser exemplaritzant i no ho fou, però que es va mantenir, a la força, fins l'any 1976 Ho vaig viure en primera persona: les expulsions, encara com alumne, el retorn ja com a professor de la Complutense, vaig cedir per Aranguren un espai i una taula al Departament d'Estètica, perquè no estigués obligat a rebre les visites, com ho feia efectivament, al bar de la Facultat de Filosofia. Les coses no van ser fàcils en els inicis de la transició. Potser mai ho han estat del tot.

Per això, en aquest moment -mig segle llarg, després dels fets rememorats, com a ressò d'aquell citat dictum proprium, convertit en principi de conducta, per aquells professors, que ampliaven aixi I'àmbit de la filosofia aplicada - caldria rellegir i/o enllestir, socialment, hui en dia, atesa la intensa i problemàtica perplexitat del panorama que ens envolta, un altre dictum operatiu, més dilatat i ambiciós encara, si cap, que estrictament podria formular-se així: Nulla politica et nulla oeconomia sine ethica.

Aquests diàlegs interdisciplinaris, dels nostres orígens, que hem comentat, activats - a peu de carrer, a peu de museu i a peu de tarima - eren, doncs, imprescindibles acadèmicament, ateses les persistents connexions que, aquesta mateixa arrel comuna —com a sectors coimplicats de la filosofia pràctica - els atorga i assigna. I una manera força eficaç de demostrar-ho fou enllestint i reforçant una àrea interdisciplinària efectiva, amb professors i becaris arribats de plurals especialitats. Un exemple directe que va fer via efectiva, i es va extrapolar tot, en efecte, com hem dit, cap a altres universitats.

En concret, les exigències del context històric contemporani, ja en plena transició política, condicionarien i determinarien, en bona mesura, els perfils de l'estètica a les nostres universitats públiques valencianes, així com reforçarien les respec tives especialitzacions, com a col-lectiu interdisciplinari en expansió. Fins i tot organitzàrem, des de l'àrea, ho recorde i ho recordareu bé, les primeres mostres d'art contemporani, gestionades i comissari- 
ades, ja als inicis de la dècada dels anys vuitanta, a les nostres universitats. Calia obrir camins, que, en efecte, continuen feraços i exemplars, en l'actualitat, en els fructífers intercanvis cultura-Universitat.

¿Quins nuclis podrien ser prioritzats, doncs, en l'estudi de l'art contemporani, des de la reflexió estètica? Era aquesta una qüestió que ens preguntàvem, força interessats, en els primers encontres, seminaris i sessions de treball interuniversitari... Sobretot gràcies a les intenses i sostingudes relacions existents, al llarg de dècades, entre les universitats públiques del nostre país. Diàlegs reforçats entre l'estètica i la història de l'art, entre la teoria de l'art i les belles arts, entre l'estètica i el disseny, també entre l'art i l'educació entre la creativitat i el compromís social.

La constitució de l'Institut de Creativitat i Innovacions Educatives (1972) i, més tard, del Centre de Documentació d'Art Valencià Contemporani (1983), tots dos dependents de la Universitat de València,

$\infty$ fou, en aquest context, una fita més, de ㄱ. Ilarg espectre. Anys després ens vàrem O bolcar, així mateix, en la constitució del $\Sigma$ CIDA de Vilafamés, en especial algunes professores i becàries del Departament. $\stackrel{\text { ह் }}{\check{c}}$
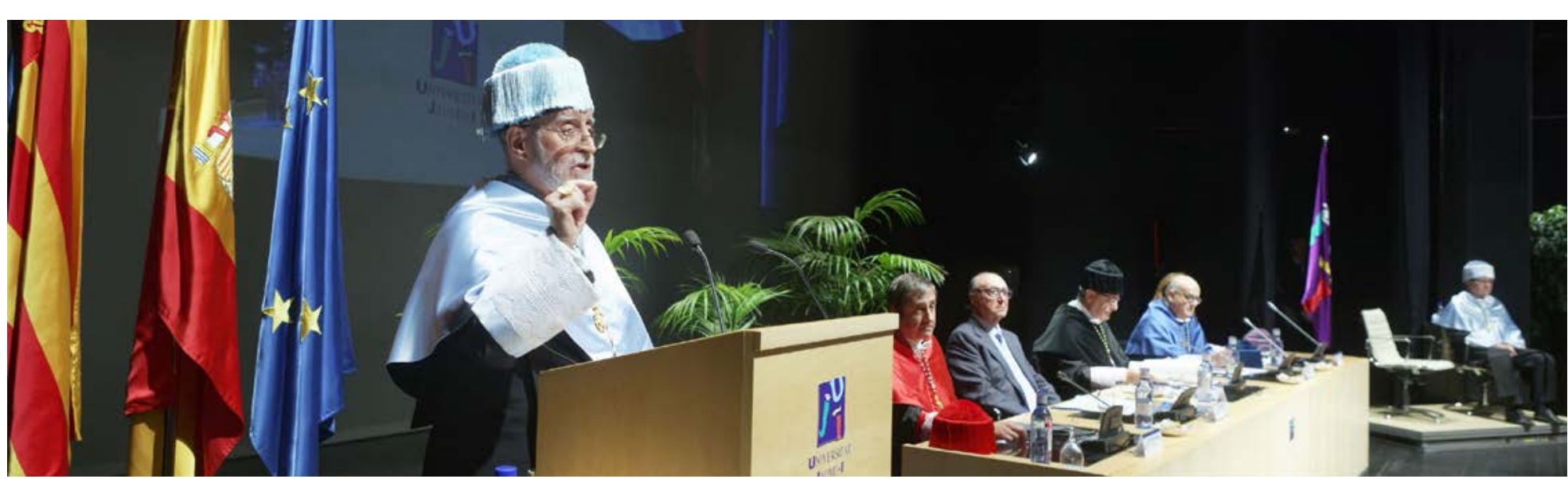

Especial incidència projectàrem, així mateix, al voltant de l'activitat de recerca i realització editora, tant en la secció bibliogràfica com hemerogràfica, vam crear col-leccions de llibres i revistes especialitzades. El nou àmbit de diàleg, entre l'estètica i l'art contemporani, ho reclamava i hi érem, per cert, un bon equip de persones entregades a aquesta finalitat. Moltes d'aquestes persones - insistesc - estan hui ací, entre nosaltres i ho celebre.

¿Com no recordar, per cert, les col.leccions de llibres: Aesthetica, de Fernando Torres editor; Art \& Filosofia, de l'editorial Nau Llibres; Cuadernos de Arte \& Comunicación de l'editorial Teorema, o Estètica \& Crítica, del Servei de Publicacions de la Universitat de València? Tota una feina i cura de seguiment compartides. En aquestes colleccions es publicaren, precisament, llibres de molts autors, que ara són destacats docents i investigadors, pe exemple, de I'UJ.

¿Com oblidar, per altra part, revistes convertides en la finestra difusora de tants treballs nostres, com CIMAL. Quaderns In ternacionals d'Art Contemporani, encapçalada, una vegada més, per Aguilera Cerni, o Reüll. Revista d'Informació Visual d'inoblidables esforços, somnis i records de tot un equip? Després, en aquesta mateixa línia d'aventures editores, en vingueren altres i noves —revistes i col-leccions de llibres - potenciades per diferents generacions d'estudiosos, amb objectius ja propis, per exemple, en aquesta Universitat. Voldria així citar Asparkía. Inves tigació feminista, iniciada exitosament el 1992 o la Revista de Estética y Arte Contemporáneo de merescut seguiment, també la «Col-lecció de Dissenyadors Valencians» $i$ la solidesa de la col·lecció «Arts», que cal recordar i donar-li suport. Ho faig per a retre justícia compartida a la memòria d'aquests assoliments de recerca i difusió, junt amb tantes publicacions, imprescindibles ja, a la bibliografia específica d'art, estètica, disseny i comunicació audiovisual, generats des d'aquesta Universitat.

Justament fa un any, en les jornades convocades per I'UNE, a Castelló, presidides pel rector, vàrem rebre, de la Unió Nacional d'Editors Universitaris el guardó a la millor col-lecció de llibres, dedicat a la tasca sostinguda que representa el conjunt de qualitat dels quaranta títols, que conformen ja «Estètica \& Crítica». Una fita compartida, per tant, amb tots els col.laboradors del projecte.

Tornant a les qüestions bàsiques del desenvolupament de la diacronia de I'àrea, cal parlar —en seguir el fil d'aques ta història, que ens preocupava, des d'un principi- de l'estudi i exemplificació de les diferents «poètiques», sorgides en els inquiets panorames artístics de cada moment. No debades estàvem disposats a trencar una llança, no en favor d'una «estètica normativa», com la que històricament, sovint, s'havia propiciat acadèmicament, sinó més aviat en potenciar el desenvolupament, en el marc de la con- 
temporaneïtat, d'una nova aesthetica. És a dir, d'una «estètica descriptiva, analítica i crítica», en relació directa amb el desenvolupament del fet artístic actual i la seua pedagogia compromesa i expansiva.

L'art assumit i comprès, doncs — ni més ni menys - que com a suma de les poètiques que, en cada conjuntura històrica, persisteixen, emergeixen i es desenvolupen. Era un repte que l'estètica havia de fer seu, a peu de camp, per a involucrar-se plenament i fer-se lloc entre la poètica i la crítica, en abordar, amb rigor, l'estudi de la història de l'art contemporani del nostre voltant, transformat, efectivament, en herència pròpia.

Estètica, poètica i crítica enteses, en efecte, com una trilogia de baules estretament corelacionades al si del fet artístic, sense oblidar, tampoc, la genuïna dimensió de l'experiència estètica, vinculada diacrònicament a l'exercici de la recepció, sense exhaurir-se, mai, de manera exclusiva en aquest àmbit, atès que, en l'actual efervescència de l'estètica filosòfica, aquesta noció capdavantera - l'experiència estètica — s'ha convertit en una categoria fonamental, directament vinculada amb l'ètica i la política, esdevinguda clau del compromís educatiu i transformador de la societat.

L'experiència estètica, en aquest sentit, no es limitaria, doncs, a una acció estrictament individual, contemplativa, receptiva i passiva enfront de l'objecte artístic. Caldria potenciar, a més a més, la versió d'una acció comunitària del subjecte, de relació amb el món, és a dir de contextualització de l'experiència, per a incrementar els possibles efectes de l'autoreflexió, l'autocrítica i la transformació sociopolítica de les experiències estètiques, palanca expandida i determinant del rerefons ètic enfront de les obres.

Érem i som conscients — senyores i senyors - de la constant metamorfosi de l'art, en el context mutant de la realitat de l'entorn. Cada dia suposa possibilitats i/o exigències, per a l'art, d'iniciar coses noves. De fet, la continuïtat i/o la seguretat pròpies d'un

Do sistema no existeixen; mai han existit, de fet, per a la creació artística capdavantera i $\Sigma$ compromesa. La seua potencialitat radica en la flexibilitat que puga demostrar per a enllaçar, anticipar, rellegir, prefigurar, transgredir i innovar.
També la capacitat per a dialogar i/o relacionar-se amb tot el que està al seu voltant li és fonamental al quefer artístic: amb la història i tot el conjunt de les demés obres, amb el públic i les seues experiències estètiques, amb la crítica i el pensament, amb la resta de les altres arts, expandint-se més enllà de les fronteres interdisciplinàries. I, per tot això, també l'estètica, junt amb les poètiques, la crítica i les experiències estètiques, són i seran dominis sotmesos a una perpètua revisió i/o transformació i intercanvis.

Sovint he pensat que l'art s'apropia — hàbilment, per necessitat i supervivència, en aquests moments de precarietat compartida que ens caracteritzen- de certes maneres de fer crítica, al si de les seues estratègies creatives. Amb aquests recursos esdevé protagonista d'una capacitat, força especial, de produir diàlegs i reflexions — no sols en el seu quefer, també, si més no, enfront de les noves experiències estètiques-que motiven i conformen el seu entorn. Es tracta d'una modalitat de producció sostenible i sustentada bàsicament en l'intercanvi d'experiències i de coneixements entre fronteres, cada vegada més amples i extenses, amb contaminacions mútues i implantacions tecnològiques creixents.

En aquest sentit, tot un complex camp d'interessos s'obri, de bell nou, per tant, a l'estètica com a filosofia aplicada, en el seu acostament a l'horitzó de l'art, el qual exigeix futur, atenció i suport. L'estètica vol ser testimoni i vol alçar acta de tot el que descobreix en els àmbits i dominis del fet artístic: diàlegs, a la fi, entre les imatges i les paraules, entre la creació i el pensament, entre l'experiència controlada i la imaginació trencadora. Sabem bé que l'art sempre fa parlar, és cert. I que necessita dir, comunicar, expressar-se i «ser parlat»o, pel contrari, mantenir silencis, deixar de ser espill i esdevenir enigmàtic, per a millor defensar-se, pot ser, en certs possibles intervals, problemàtics i de control, de la difícil existència compartida en eixe voltant.

De fet, enmig de totes aquestes metamorfosis de l'entorn artístic, que hem viscut i vivim, dècada rere dècada, tant la Càtedra d'Estètica com la seua creixent àrea interdisciplinària - mai abans existents històricament en les nostres universitats valencianes - van perfilar la seua implantació i les seues programacions actives, les quals partiren - in nuce - des de la Facultat de Filosofia, per a impartir docència a més, cal 
recordar-ho, en Història de l'Art, en Filologia, en Belles Arts, en Arquitectura, en Enginyeria, en Ciències de la Música i també en l'àmbit del disseny.

Hi ha tot un riu de tesis doctorals, com a prova determinant, d'aquesta història. Sens dubte, un evident rosari d'esglaons d'activació acadèmica i social, al costat de nombrosos records compartits, per moltes persones, amb les quals tants deutes intel.lectuals, de gestió, suport i afecte sóc conscient que mantenim.

Aquest era, al cap i a la fi, el contingut o també el teixit descriptiu que desitjàvem embastar, en la Lectio de hui, amb un evident perfil pragmàtic, com a agraïment a les nostres universitats, les quals varen facilitar la realització de molts dels nostres somnis, transformats, a més, en projectes viables, al llarg de mig segle de convivència. Es tracta, ni més ni menys, de la història d'una disciplina que hem fet nostra i hem ajudat a consolidar i a créixer, entre tots, sempre movent-nos, com funàmbuls, sobre perilloses i flexibles cordes, enmig de la dubtosa i problemàtica frontissa entre l'art i la realitat, entre la força de la imaginació $i$ les exigències de la reflexió, sobretot en moments de precarietat, limitacions i crisi.

$+++++++++++++++++$
Gràcies, doncs - força especials - a la benvolguda Universitat Jaume I, per aquest nomenament de Doctor Honoris Causa, que em facilita -- amb lloable generositat $\mathrm{i}$ implicació de moltes persones-- formar part d'aquesta meritòria institució i que, per cert, mai no oblidaré.

Voldria, també, rememorar a la meua família, en aquesta conjuntura, per tantes coses... I moltes gràcies, per descomptat —intensament sentides - a totes les nombroses persones presents, per la seua assistència, atenció, afecte i companyia.

Hi ha un altre dictum que fou emprat moltes vegades pels nostres il.lustrats, el qual sempre em va colpir i més d'una vegada he utilitzat, per la meua banda. Hui, voldria tornar-lo a fer meu. Quod potui feci, faciant meliora potentes. He fet el que he pogut. Altres vindran darrere, més preparats, que ho faran força millor.

Castelló de la Plana, 21 novembre de 2017, al Paraninf de la UJ. Nomenament Doctor Honoris Causa. Prof. Romà de la Calle.

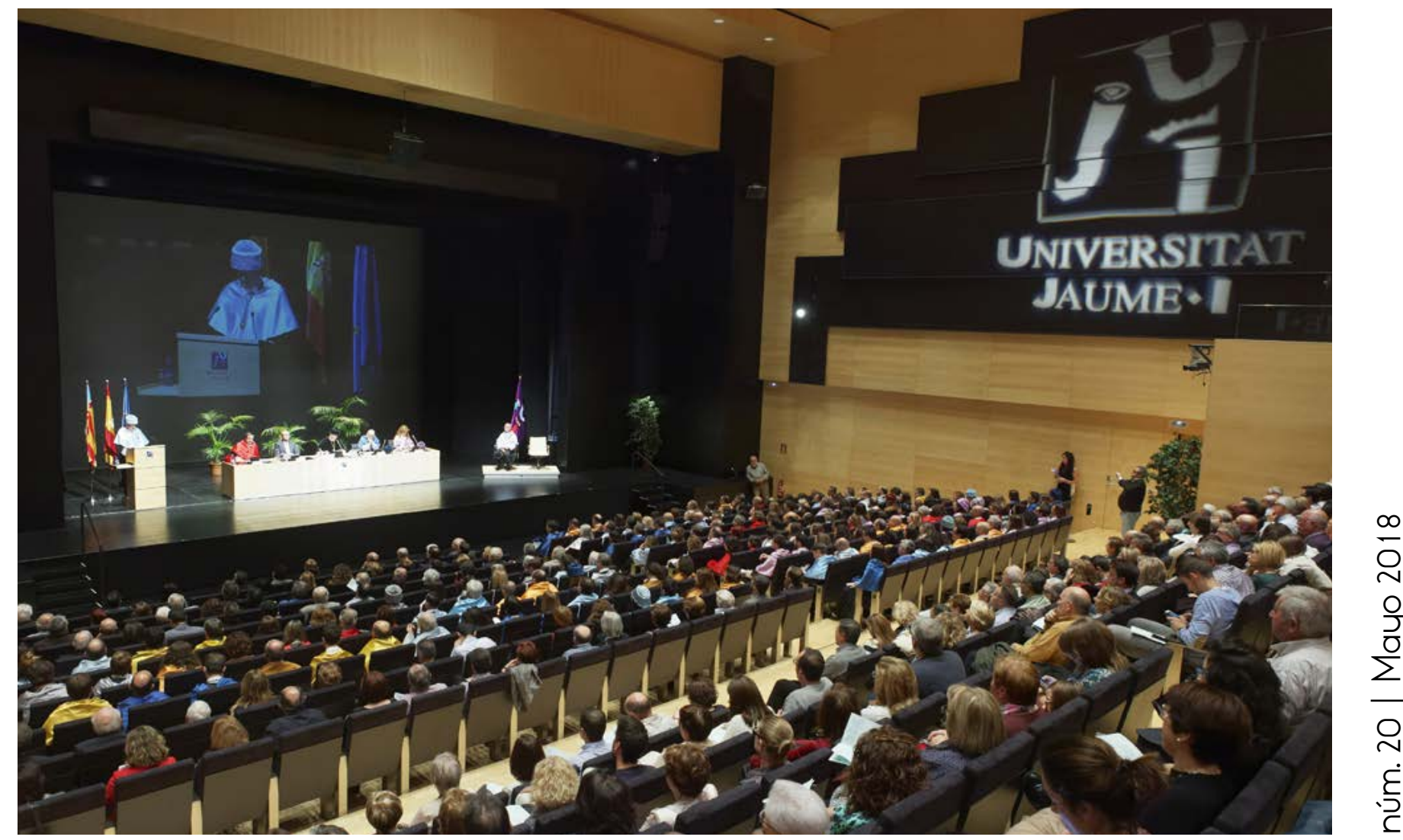

Sumario| 143 